\title{
Nonlinear Integrated Design of Lattice Domes with Supporting Substructures
}

\author{
Ali Etemadi*, Can Balkaya** \\ *Department of Civil Engineering, Faculty of Engineering and Architecture, Istanbul Gelisim University, Istanbul, Turkey. \\ ** Department of Civil Engineering, Faculty of Engineering and Architecture, Istanbul Gelisim University, Istanbul, Turkey. \\ (aetemadi@gelisim.edu.tr, cbalkaya@gelisim.edu.tr)
}

${ }^{\ddagger}$ Corresponding Author; Can Balkaya, Department of Civil Engineering, Istanbul Gelisim University, Istanbul, Turkey,

Tel: +90 212422 7020, Fax: +90 212422 7401, cbalkaya@ gelisim.edu.tr

Received: 14.06.2017 Accepted: 21.07.2017

\begin{abstract}
This paper investigates the response interaction between reinforced concrete substructure and steel raised lattice roofing. The viewpoint of dynamic stability and nonlinear seismic behavior are considered as both geometrical and material nonlinearity. In particularly, dynamic stability performance of single layer Diamatic domes located on peripheral reinforced concrete columns is investigated under vertical loads and seismic excitation. Different supporting structures with rigidity and reinforcement detailing of the circular peripheral columns are considered in the integrated design. The vibration modes for the lattice dome with and without substructure effects are studied. Results show that high capacity substructure or fixed supporting assumption may lead to unsafe stability performance as well as uneconomical designs. The integrated design of composite system, RC supporting substructure and upper lattice roof could be provided superior dynamic stability performance when compared to the design without supporting substructure.
\end{abstract}

Keywords Integrated design, Lattice dome, Dynamic instability, Budiansky-Roth criterion, Mander model, PEEQ, Supporting substructure

\section{Introduction}

Lattice domes are a popular kind of space structures use for covering large sporting and cultural areas as sports centers, halls, gymnasiums, theaters, hangars, exhibition centers and other wide span roofs. Likewise, being lightweight, having a high degree of indeterminacy, high rigidity, satisfactory seismic vulnerability, being simple to produce, being fast to assemble, being fully prefabricated, which means there is no need to weld on site are the main reasons that may be outlined for widespread use of lattice roof shells. From the perspective of seismic vulnerability, lightness and spatial load distribution mechanisms that result in lower internal forces may be underlined in less damage of lattice shells when exposed to when compared to neighbor conventional buildings.

Steel lattice shells are usually supported by peripheral columns, reinforced concrete (RC) frames and wall substructures to provide architectural requirements and increase usable capacity of buildings. In design practice, upper lattice roofs are modeled with fixed boundary supports and the dynamic response interaction effects between the roofs and supporting substructure are not taken into account. Whereas it is known that failure modes are well correlated with dynamic interaction of both parts of structure, which may bring about significantly different results compared to fixed support case. This is particularly valid when system passed elastic ranges. We learned from past earthquakes that a weak point of lattice shells located at the vicinity of anchor supporting. From this perspective, the seismic assessment of supporting substructures on dynamic responses of whole system is crucial and need more detailed studies.

Several studies are carried out investigating the influence of rigidity or/and flexibility of boundary support on dynamic behavior of raised lattice roofs (Moghaddam, 2000; Hazrati and Chenaghlou, 2007; Takeuchi et al., 2004; Cao et al., 2004; Wang et al., 2008). Moghadam (2000) examined the seismic response of double-layer barrel vault roofs, with and without the sub-columns, with an emphasis on post buckling behavior of roof elements. Hazrati and Chenaghlou (2007) investigated dynamic effect of rigid and flexible supporting substructures. The support reactions and the effective frequency content are other issues that were discussed. 
Cao et al. (2004) compared dynamic responses of three different raised cylindrical lattice shell models (model with concrete supporting substructures, hinged supports and elastic supports) to obtain an appropriate analytical model. In this way, the performance of combined system and influence of some structural parameters, including height and strength capacity of columns are investigated.

It was found that an interaction between lattice roof and substructure may lead to unsafe results and cannot be overlooked. Wang et al (2008) examined seismic response of the elevated single layer oval shell sit on peripheral $\mathrm{RC}$ columns, in the case where, some regular roof parts of lattice roof replaced by Buckling-Restrained-Braces (BRBs). Recently, J. Sun et. al (2014) and J. Yan et.al (2016) also emphasized the important role of the substructure in the design.

Despite many new achievements of accomplished studies in most of them, only an elastic behavior of supporting substructures is incorporated into dynamic analysis. While, feasible roof nonlinearity and unexpected failure mode of supporting structure as well as unrealistic large seismic forces of roof members at the vicinity of boundary supports as well as overestimate forces of connections are some consequences those could be outlined, can be affected from linear assumption of supporting substructures. In this study, it is intended to achieve more realistic seismic behavior of inelastic composite system by considering both the geometrical and the material nonlinearity of supporting substructure.

The integrated design of the composite system in the presence or absence of supporting structures is examined. It is planned to clarify the overview appropriate design methodology to consider the integrated design elevated lattice domes supported by peripheral columns. However, in most cases steel domes are designed and constructed with fixed supported assumptions like dome is stayed on the ground. But this assumption is doing not represent the real behavior.

\section{Modeling and Method of Analysis}

The geometry of the analytical models is built up using the FORMIAN platform (Nooshin and Disney, 2001). The program has been developed on the basis of the Formex algebra that enables one to form different geometrical surfaces of lattice shells very easily through changing of some control parameters. Several single layer spherical domes with Diamatic configuration in the presence or absence of peripheral columns are generated. The output of the Formian model is converted into an input file of the ABAQUS (Karlsson and Sorensen 1999) analyzer to perform dynamic instability analyses. The geometry and surface configuration for both types of dome models are shown in Fig. 1. The openings of domes are 40 $\mathrm{m}$ and raise-span $(\mathrm{f} / \mathrm{L})$ ratios are $1 / 5$. Likewise, the sweep angle is $A=40$, frequency, $m=7$; number of sectors, $n=6$; and joint's form of dome members are rigid connections.
The moment resistance substructure frames that including pipe member columns being supported by pin connections is considered. The tension ring is circled around the lattice dome and the connecting links between the tension ring and the supporting substructure are pin joints. The requirements for simplifying principal modes are clarified and distributions of maximum acceleration in both horizontal and vertical directions are introduced through the simple expression as a function of their own period ratio and mass proportion of dome and supporting substructure. The pipe sections with size of $\varnothing 160 \times 6.5 \mathrm{~mm}$ are used for peripheral ridge components. Remaining components of domes, including the rib members are orbital with $\varnothing 114 \times 3 \mathrm{~mm}$ diameter in size.

The structural RC substructure models are designed for combined gravity and seismic effects, in compliance with the Turkish seismic code specifications (TEC, 2007). The supporting RC columns are prepared and detailed according to the Turkish standard for design and construction of reinforced concrete structures (TS-500, 2000).

The supporting substructures composed of twentyfour $\mathrm{RC}$ columns with $\mathrm{H}=6.0 \mathrm{~m}$ height and flexural stiffness, that arranged around the dome, periphery. Each column placed under the peripheral ridge nodes one among. The column heights are $6 \mathrm{~m}$ and are located at a distance of the $5.22 \mathrm{~m}$. The diameters of circular sections and in turn reinforcement details varied to cover the full range of support conditions, from rigid to flexible in comparison to those of the upper domes. The RC column diameter changed in range of $50 \mathrm{~cm}$ to $90 \mathrm{~cm}$, which symbolized through D50 to D90 at an acronym of models.

In first stage, the single dome restrained by fixed supports, is analyzed (Fig. 1.a). The mechanical properties and reinforcement detail of supporting ring columns are changed to adjust both rigidity and strength capacity ratio of the substructures and upper domes given in Table 1. The notation shown in Table 1 defined geometry of the composite structure, for example, the "G5H6D50" symbolizes the model with raise-span ratio equal to $1 / 5$ and peripheral supporting columns with $6 \mathrm{~m}$ height and circular section of the $50 \mathrm{~cm}$ diameter. The "G5" notation denotes the lattice dome without supporting substructure.

The transverse reinforcement of all columns are $\varnothing 10 / 10 \mathrm{~mm}$ stirrups. It is assumed that concrete compressive strength equal to $30 \mathrm{MPa}$ (C30). The yield strength of both longitudinal and transversal reinforcement is considered equal to $420 \mathrm{MPa}$. The Poisson's ratio is $v=0.3$. The longitudinal reinforcement arrangement of the D60 model is shown in Fig. 2.

The comparison made between dynamic performances of the steel lattice dome located on the RC supporting structures with different rigidity and strength capacity ratio towards the dome shell. 


\subsection{Elements Used for Simulation and Material Properties}

The lattice domes tabular beams and peripheral RC columns are modeled using the Pipe-31 and Beam-31 elements from ABAQUS element library. The constitutive relation of mild steel tubular member material (Q235) is assumed an elastic-perfectly plastic model. The other mechanical characteristics of the steel tubular members are: $\quad \sigma_{y}=235 \times 10^{6} \mathrm{~N} / \mathrm{m}^{2}, \quad E=2.06 \times 10^{11} \mathrm{~N} / \mathrm{m}^{2}, \quad v=0.3$, $\rho=7850 \mathrm{~kg} / \mathrm{m}^{3}$. The mechanical properties of RC subcolumns are: $\mathrm{C} 30, \mathrm{E}=2.5 \times 10^{10} \mathrm{~N} / \mathrm{m}^{2}, v=0.2, \rho=2500$ $\mathrm{kg} / \mathrm{m}^{3}$ and the specified compressive strength is $f_{c k}=$ $30 \mathrm{MPa}$. In as much as the Beam 31 element cannot incorporate post-yielding degradation properties, stiffness softening, strength deterioration and concrete confinement characteristics due to reinforcement into the calculations. The Mander confined RC model is used and developed in "MATLAB" in order to incorporate post yielding properties of substructure columns into analysis through updating input file of whole model in the ABAQUS analyzer software.

It is assumed that an inelasticity of RC columns initiate when an internal compression force reaches to 40
$\%$ of the concrete compressive strength $\left(0.4 \mathrm{f}^{\prime} \mathrm{c}\right)$ and upon passing this limit, the behavior curve, followed predefined Mender strain-stress envelope (Mander, 1988). Other post yielding properties of cross sections such as; tension stiffening; and failure criteria are defined in to the input file in a similar way. An example of stress-strain relationship (G5H6D60 column model) is shown in Fig. 3.

\subsection{Gravitational Loads and Ground Motion Data}

The roof load was taken as $1.47 \mathrm{kN} / \mathrm{m}^{2}$. All loads and self-weight of structures were treated as lumped masses and concentrated at roof nodes. For this purpose, roof nodes were defined as a mass element with an amount equal to $12.68 \mathrm{kN}$. The analyses were conducted in two steps. In first step, the dome was allowed to deform under the dead loads, then given ground motion record was applied in to model. The ground motion recorded at the "EL-CENTRO- Imperial Valley, Irrigation District" in 1940 was adopted to quake the system. The record selected has impulsive pulses in the beginning of time series, which could be led to severe structural damages by transmitting high energy to structure. That is why, the first ten second of tri-axial ground motion were adopted in following dynamic performance assessments.

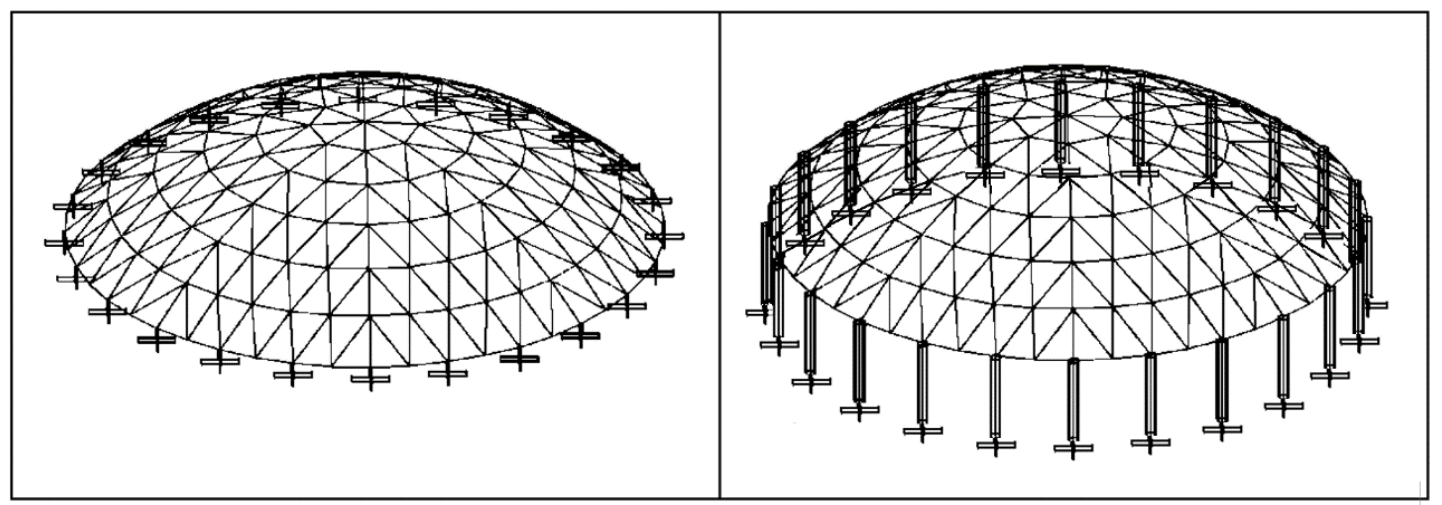

(a) without supporting structure

(b) with supporting structure

Fig. 1. Geometric models of the Diamatic domes.

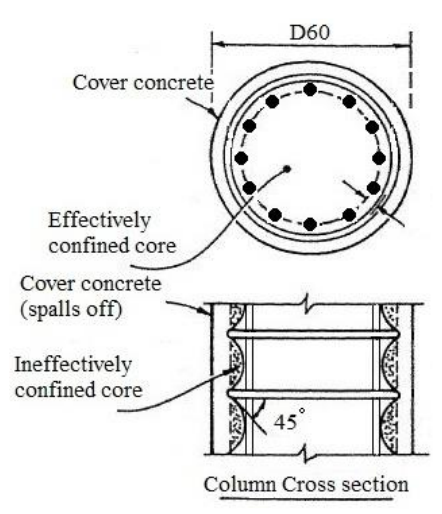

Fig. 2. Reinforcement detailing of substructure.

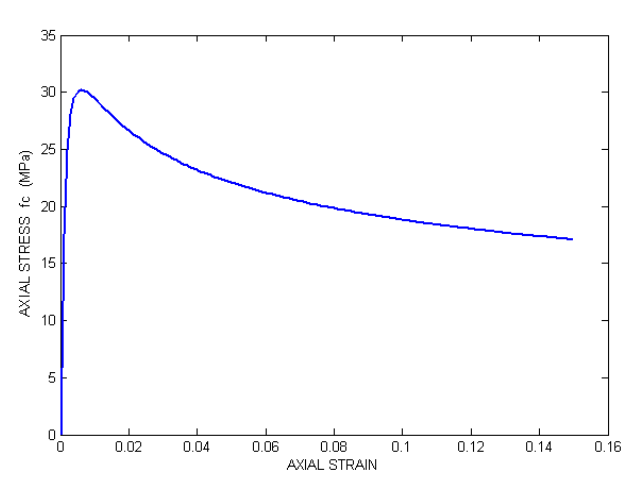

Fig. 3. Mander model stress-strain curve for circular column of D60 model (fck=30 MPa). 
Table 1. Cross-section and material properties of substructure peripheral columns

\begin{tabular}{c|ccc}
\hline Models & $\begin{array}{c}\text { Diameter } \\
(\mathrm{cm})\end{array}$ & Rebars & $\begin{array}{c}\text { Flexural } \\
\text { Stiffness } \\
\text { Kc }(\mathrm{kN} / \mathrm{m})\end{array}$ \\
\hline G5H6D50 & D50 & $10 \Phi 26$ & 1065.2 \\
G5H6D60 & D60 & $12 \Phi 28$ & 2208.9 \\
G5H6D70 & D70 & $16 \Phi 30$ & 4092.3 \\
G5H6D75 & D75 & $16 \Phi 32$ & 5392.9 \\
G5H6D80 & D80 & $2 \times 16 \Phi 24$ & 6981.3 \\
G5H6D85 & D85 & $2 \times 16 \Phi 25$ & 8897.2 \\
\hline
\end{tabular}

\section{Dynamic Analysis of Integrated Dome Structures with Supporting Substructure}

The dominant natural frequencies and mode shapes with greater mass participation factor are determined through the modal analysis. The dominant frequencies are required to create the Rayleigh's coefficient in assembling a damping matrix. Contrary to conventional buildings, where first few modes dedicated large percentage of mass participation, the spatial type structures have many vibration modes with significant mass participation factor ratio. The reason may be coming from the high degrees of freedom and wide spreading of masses throughout roofs. The Eigen frequencies ordinates for different supporting structure models and without supporting structure case are plotted in Fig. 4.

It is seen that frequencies ordinates corresponding to lower modes, which mainly belongs to prevailing horizontal movement, for domes with supporting substructures are less than those of single dome structures. Likewise, the natural frequencies are almost the same after the fifth mode. The reason underlying such similarity may be due to the high axial stiffness of columns in all cases and its ineffectiveness while vertical movements are prevailing. The higher modes of space structures are effective as well. The frequencies of lower dominant vibration modes are tabulated in Table 2.

Table 2 Comparison of free vibration frequencies (Hz) for some lower modes

\begin{tabular}{ccccccc}
\hline Order of Frequency & & 1 & 3 & 5 & 7 & 10 \\
\hline No Substructure & G5 & 3.657 & 4.062 & 4.087 & 4.182 & 4.188 \\
& $\varnothing 50$ & 1.638 & 2.222 & 3.67 & 3.69 & 3.84 \\
Domes & $\varnothing 60$ & 2.143 & 2.928 & 3.713 & 3.781 & 3.859 \\
with substructure & $\varnothing 70$ & 2.606 & 3.723 & 3.745 & 3.884 & 3.902 \\
(Column & $\varnothing 75$ & 2.794 & 3.763 & 3.898 & 3.899 & 4.001 \\
Sections) & $\varnothing 80$ & 2.948 & 3.783 & 3.916 & 3.944 & 4.019 \\
& $\varnothing 90$ & 3.170 & 3.825 & 3.950 & 3.963 & 4.11 \\
\hline
\end{tabular}

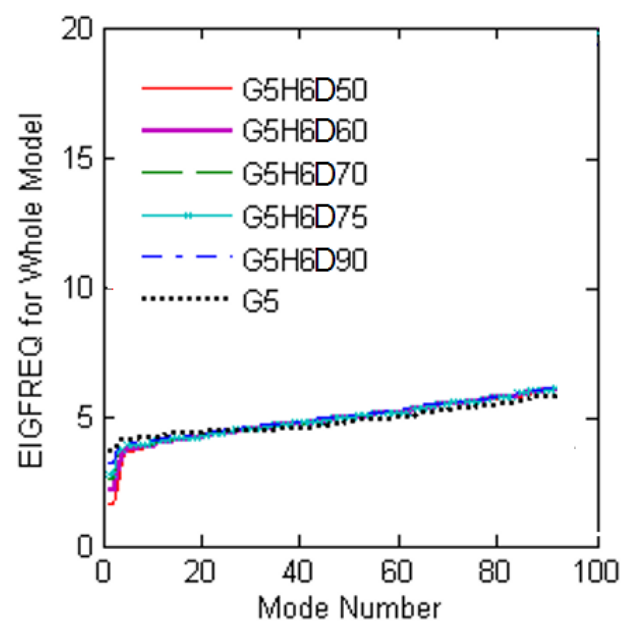

Fig. 4. Frequencies corresponding to mode numbers obtained from modal analysis.

The upper steel lattice roof and the supporting $\mathrm{RC}$ substructure composed of two structural materials, which in turn lead to different energy loss mechanisms at different parts of structural system, for this reason distribution of damping forces will not be similar to distribution of the inertial and elastic forces and in turn, damping matrix will be non-proportional (Clough and Penzien 2003). To construct the non-proportional damping matrix, firstly proportional matrix is developed for each distinct part of the structure and then the damping matrix is formed through direct assembly. The modal damping of steel upper lattice dome is taken two percent of critical damping while those of the concrete supporting substructure would be five percent. In this way, the Rayleigh's coefficients are introduced to the analyzer for each part of models, individually. 
To create a damping matrix with Rayleigh's method, the damping matrix coefficients ( $\alpha$ and $\beta$ ) should be in hand. The mode shapes \#2 with supporting substructure columns G5H6D90 model and dome with unsupported substructure model (G5) are illustrated in Fig. 5. As shown in Fig. 5, the second mode shapes for both models that exhibit lateral motion are compared. Lattice dome supported with columns has higher period value. Also P-
Delta effect will be playing an important role for the dynamic response of structure with sub-columns as well as the support conditions at substructure and upper dome connections. The local displacement is higher in the dome without substructure case as compared to the elevated dome because of the part of energy dissipated in the substructure peripheral columns.

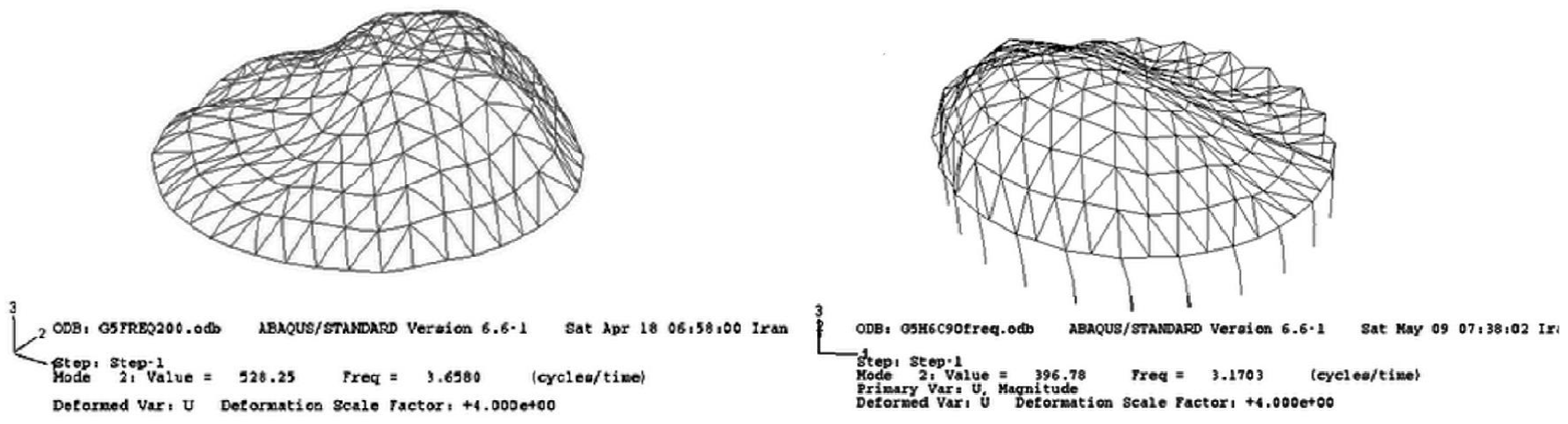

Fig. 5. Dominant mode shapes of model D90 with and without supporting substructure .

\section{Discussion of Integrated Design Results}

To evaluate dynamic performance, the structural model (see Table 1) are subjected to given ground motion at different intensities, such that the peak ground acceleration is increased stepwise and dynamic stability of the whole system are examined. Supporting substructures with different strength and rigidities in addition to a fixed boundary support (single dome) are considered as detailed in Table 1. More than a hundred nonlinear time history analyses are carried out. The dynamic buckling Lyapunov's Budiansky-Roth (1962) criterion was adopted to evaluate dynamic resistance loss of systems. The Budiansky-Roth criterion firstly applied by Budiansky and Roth to understand critical conditions for a pressureloaded, clamped, shallow, thin, spherical shell. Using this method, the govern equations of motion solved for several values of loading parameter, i.e. starting from a small quantities and incrementing its severity.

The equivalent plastic strain (output variable PEEQ) parameter is examined and the maximum vertical displacements of apex node of domes are adopted as reference point to represent dynamic performance of systems. The PEEQ used to evaluate the yield condition of the beam element tube section. It is the total accumulation of plastic strain to define the yield surface size and obtained by integrating the equivalent plastic strain rate over the history of the deformation. Essentially it is a scalar measure of all the components of equivalent plastic strain at each position in the model, somewhat like Von Mises stress that is a scalar measure the shear stress at a point and for loading with reversals. The zero values of the PEEQ represent that there is no plastic yielding in the cross section, so that it always grows with development of plastic deformations.

The nonlinear dynamic analysis is performed in stepwise. Firstly, the model with a high capacity substructure (G5H6D90) is exposed to stepwise incrementing uniaxial signal. Then analysis is repeated with increasing the peak ground acceleration amplitudes. The peak displacements of reference apex node platted corresponding to the peak ground acceleration intensities. The displacement time series of the dome apex node are shown in the Fig. 6 and the displacement response graphs of the vertex node corresponding to the peak ground acceleration for the G5H6D90 model is illustrated in Fig. 7.

The results show that, the structure remains stable until ground motion intensity increased up to 800 gals $(0.8 \mathrm{~g})$. the structural components performed well in elastic range and small changes in response displacement exhibited. The peak displacement response of reference node raised abruptly once acceleration intensity reach to 900 gals $(0.9 \mathrm{~g})$, plasticization of roof components initiated and in turn dynamic resistance of structure are lost (see Fig. 7). Therefore, the dynamic instability factor tolerated by this method based on the Budiansky-Roth criteria, determined as 900 gals (0.9g). 


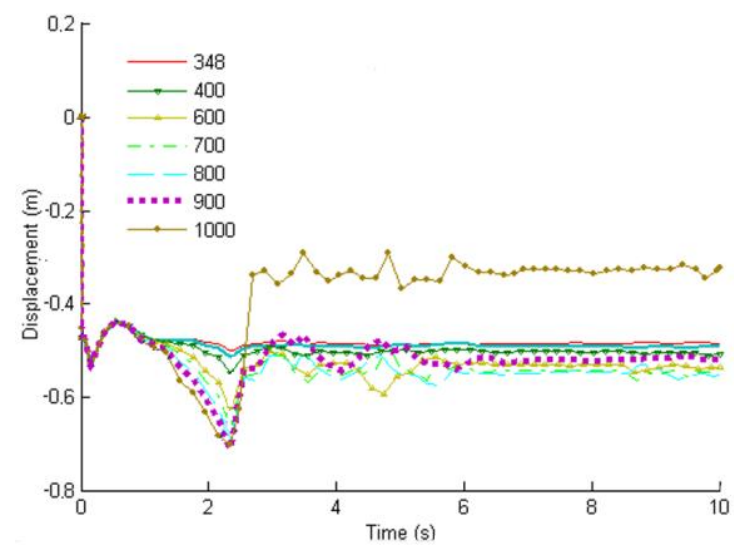

Fig. 6. The displacement time history of the apex node under given ground motion with different intensities.

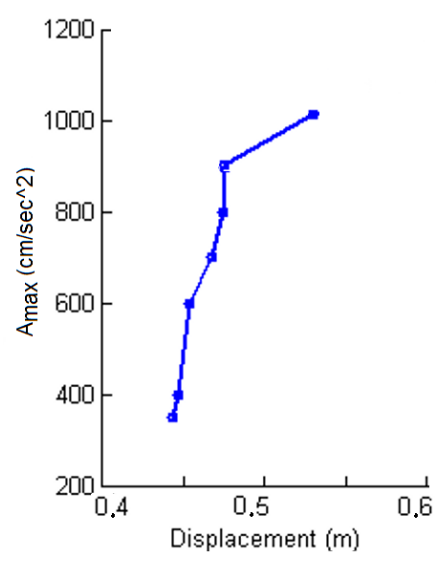

Fig. 7. The maximum displacement response of the dome apex node (G5H6D90 model).
Fig. 8 shows the dynamic failure mechanism of high capacity supporting substructure model. The failure mode is similar to that of single lattice dome, i.e., the supporting peripheral columns do not affect the yield mechanism pattern and plasticization location. A similar procedure repeated for the rest of structural models. Both uniaxial and tri-axial ground accelerations of El Centro earthquake are applied to evaluate dynamic failure of the combined systems. Later, the section dimension and reinforcement details of peripheral circular RC columns are modified to reach weaker supporting substructure.

Result shows that reduction of the cross section from $\varnothing 75 \mathrm{~cm}$ diameter (G5H6D75 model) to $\varnothing 70 \mathrm{~cm}$ (G5H6D70 model) influence failure mechanics. The failure mechanism and location of yielding shifted from an upper dome to supporting substructure. The yielding mechanism pattern for both the G5H6D75 and the G5H6D70 models seen in Fig. 9.

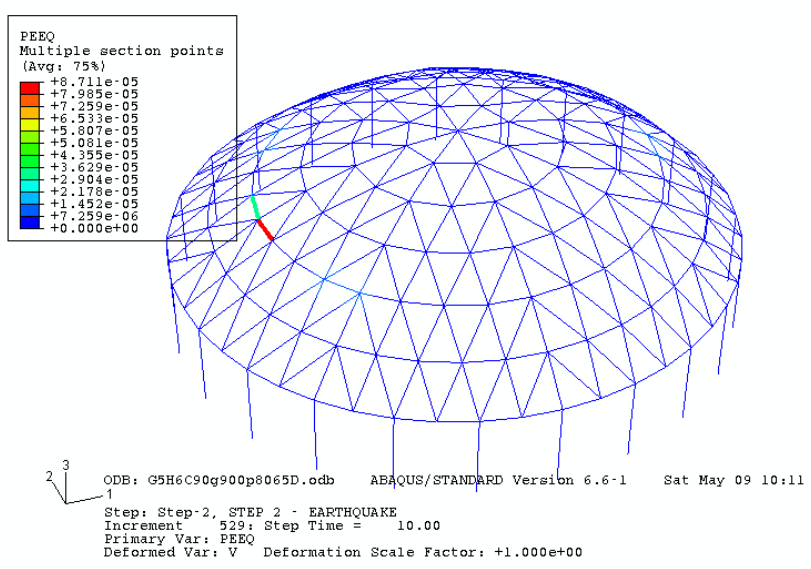

(a) Model G5, single dome

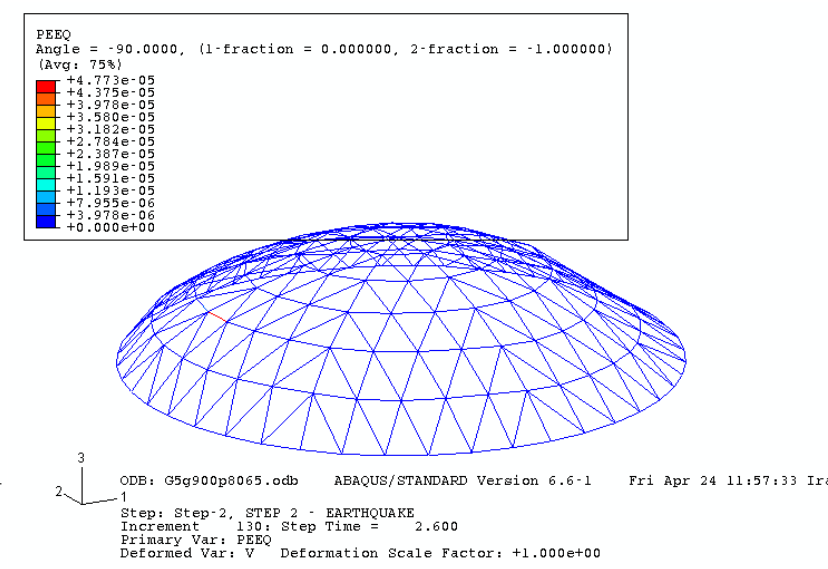

(b) Model G5H6D90

Fig. 8. The location of plasticization beginning for the rigid supporting substructures. 


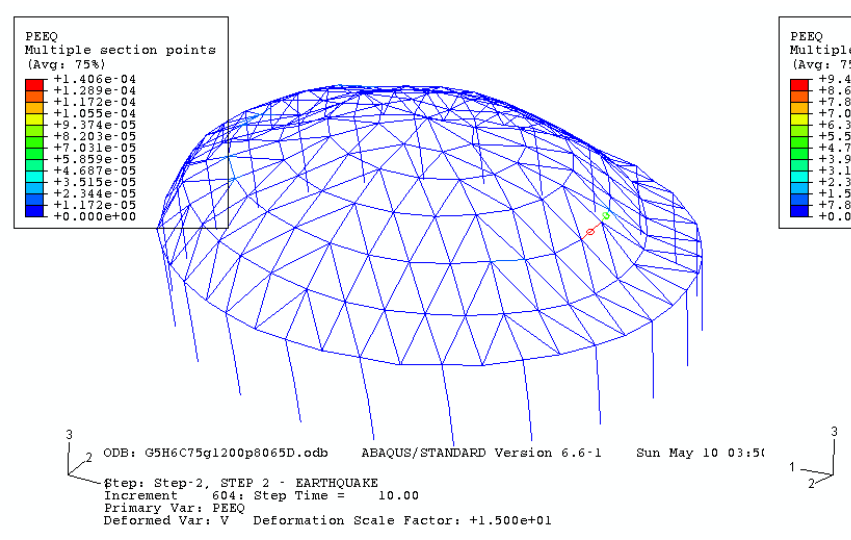

(a) Model G5H6D75

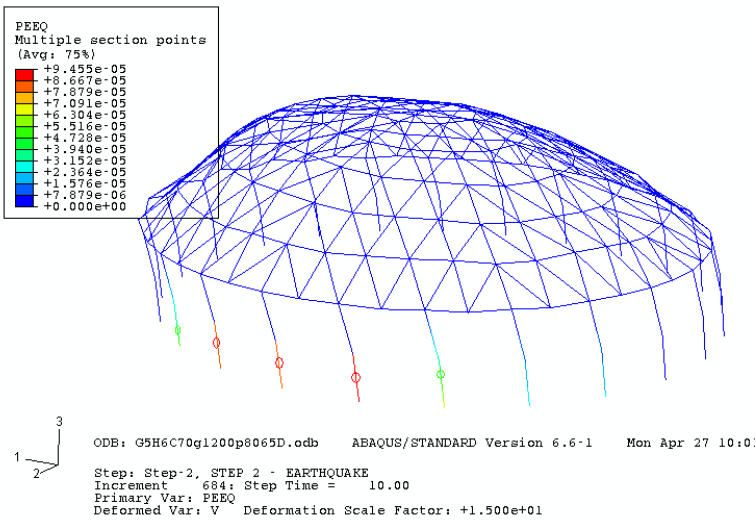

(b) Model G5H6D70

Fig. 9. The location of failure occurrence for weak substructures.

The dynamic instability levels under the uniaxial 1D (NS component) and triaxial 3D ground motions are shown in Fig. 10. Each chart represents rate of dynamic instability factor in term of peak ground acceleration intensity. The highlighted column charts in denote systems those dynamic failures initiated from roof members and distributed over the surface and the light color columns belong to structural systems that the failure mechanism generated from supporting ring columns.
A comparison of two graphs (Fig. 10) shows that, the dynamic resistance located at a higher altitude for uniaxial excitation, than corresponding tri-axial excitation scenarios. Graphs demonstrated that uniaxial excitation may leads to an underestimated evaluation of dynamic stability level for such structural complexes. It seems employing all three components of ground motion is necessary for more realistic estimation of dynamic resistance performance of raised lattice roofs.

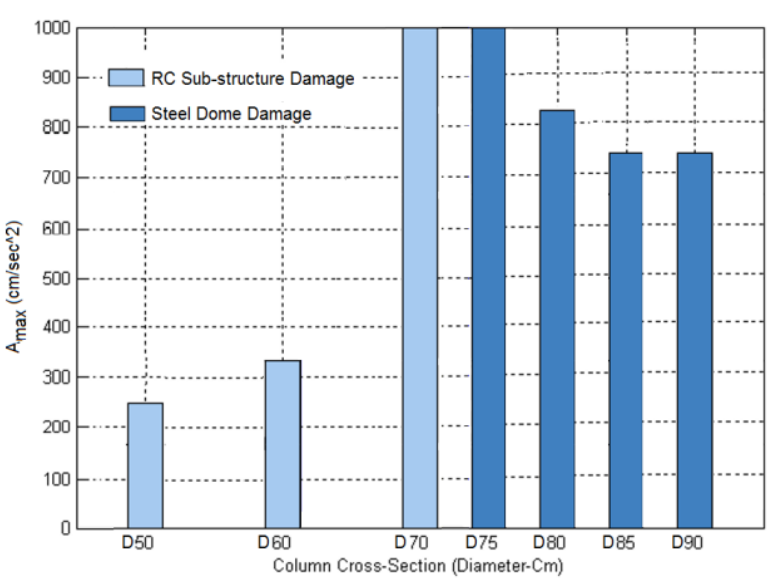

(a) Under uniaxial 1D ground motion (NS component)

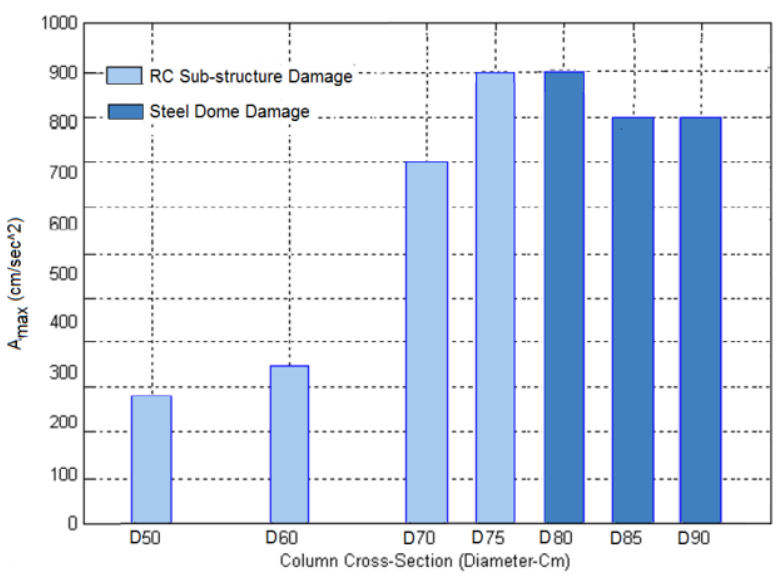

(b) Under triaxial 3D ground motion

Fig. 10. Corresponding acceleration amplitude of dynamic failure resistance of structural models with supporting columns.

Furthermore, it is observed that seismic performance of upper dome may be affected by supporting substructure responses. That is to say, when substructures strength is higher than those of upper domes, the dynamic stability performance becomes similar to fixed support roofs. Likewise, it is seen that the proportional rigidity ratio of the upper dome and substructure improves dynamic instability, provided that the structural components of supporting substructure behave in elastic limits. The proportional rigidity ratio of both part of system result in constructive and beneficial interaction between them in terms of internal force distribution and ductility of system, regardless of failures occurring in the upper roof or the peripheral sub-columns.

It is clear that, poor performance of peripheral columns disturbed serviceability, and the system loose service capabilities even in moderate ground motions. For instance, in Fig. 10 both systems undergo to ground motion at same hazard level, the G5H6D80 model shows the upper dome failure mode. In contrast, failures initiating from the sub-columns in the G5H6D75 model. It is observed that regulating the ratio of strength capacity of 
supporting substructures with upper roof structures makes that initial forces of roof members are partly reduced, particularly at vicinity of the connecting locations to a supporting substructure. The most vulnerable places of lattice roof damages generally seen at support or roof members those close to boundary supports, that it is observed in the previous earthquakes.

\section{Conclusions}

An analysis results suggest in general, that:

- The lattice domes have a high dynamic resistance with respect to common building structures such that under moderate ground motions, lattice roofing elements remain in inelastic range. The lightweight of lattice roofs as well as its spatial load distribution mechanism is the main reason underlying satisfactory seismic performance.

- It is desired to use triaxial seismic excitation when evaluate the dynamic stability performance of raised lattice roofs. Applying uniaxial excitation may result in overestimate stability performances.

- Owing to high axial rigidity of the supporting subcolumns, vertical movement modes and corresponding frequencies are almost the same for all structural models, whereas dominant horizontal movement modes and related frequencies are varied, depending on the rigidity of the supporting substructure that seen at lower frequencies.

- Lattice dome supported with columns has higher period value. Thus, such a flexible system will have higher energy dissipating capacity through the higher deformation ability.

- P-Delta effect will be playing an important role for the dynamic response of structure with sub-columns as well as the support conditions at substructure and upper dome connections.

- The local displacement is higher in the dome without substructure case due to the part of energy dissipated in the substructure peripheral columns.

Regardless of the fact that failure mechanisms initiate from upper or supporting substructure, the proportional rigidity ratio between them give rise to better dynamic performance of the whole system in comparison to the fixed support model without supporting substructure model. The weak columns affect serviceability level due to yielding of the supporting substructure prior to reaching ultimate dynamic resistance of the upper domes.

It seems that considering the fixed supports or highly resistant substructure assumption will be unsafe and uneconomical designs. Thus, integrated design will be necessary for real nonlinear behavior considering seismic load effects due to the elevated height and composite interaction effect at the connections. In practice, there is needed for further investigation to reveal dynamic response interaction between both parts of such composite structural systems.

\section{References}

[1] Budiansky B. and Roth R. S. (1962), "Axisymmetric dynamic buckling of clamped shallow spherical shells," (NASA TN D-1510), collected papers on Instability of Shell Structures.

[2] Cao Z., Xue S.D. and Zhang Y.G. (2004), “Analytical model and vibration control for shells", IASS Symposium, Montpellier.

[3] Clough R.W. and Penzien J. (2003), "Dynamics of structures", Computers and Structures, Inc. PP.242245, Third Edition

[4] Fan F. and Shen S. Z. (2004), "Study on the dynamic strength failure of reticulated domes", IASS Symposium, Montpellier.

[5] Hazrati Y. and Chenaghlou M. R. (2007), "Effect of rigid and flexible support to seismic behavior of double layer barrel vaults," 2th National conference of spatial structures, Tehran, Iran.

[6] Karlsson H. and Sorensen (1999), ABAQUS/Post Manual, Version 5.8, Pawtucket, RI, USA.

[7] Mander J., Priestley M. and Park R. (1988), "Theoretical stress-strain model for confined concrete," American Society of Civil Engineering (ASCE).

[8] Moghaddam H. (2000), "Seismic behavior of space structures", International Journal of Space Structures, Vol. 15, No. 2, pp. 119-135.

[9] Nooshin H. and Disney P. (2001), "Formex configuration processing 2", International Journal of Space Structures, Vol. 16, No. 1.

[10] Sun J., Li H., Nooshin H. and Parke Gerard A.R. (2014), "Dynamic Stability Behavior of Lattice Domes with Substructures", International Journal of Space Structures.

[11] Takeuchi T., Ogewa T., Nakagawa M. and Kumagai T. (2004), "Response evaluation of medium-span lattice domes with substructures using response spectrum analysis", IASS Symposium, Montpellier.

[12] Turkish Earthquake Code (TEC, 2007). Specification for buildings to be built in seismic zones, Ministry of Public Works and Settlement Government of Republic of Turkey.

[13] TS-500 (2000). Requirements for design and construction of reinforced concrete structures. Turkish Standards Institute.

[14] Wang X., Chen J. and Wu Ch (2008), "Dynamic analysis of single layer lattice shell with BRBs", Proceedings of the 6th International Conference on Computation of Shell and Spatial Structures, IASSIACM, Cornell University, Ithaca, NY, USA.

[15] Yan J., Qin F., Cao Z., Mo Y.L. (2016), "Mechanism of coupled instability of single-layer reticulated domes", Engineering Structures, 158-170. 